ГORIGINAL ARTICLE

Volume 14 Issue 22019

DOI: 10.21315/aos2019.14.2.380

ARTICLE INFO

Submitted: 19/03/2019

Accepted: 04/09/2019

Online: 30/12/2019

\section{Periodontal Disease in Patients with Type 2 Diabetes and Its Relationship with Dry Mouth Condition}

\author{
Norsila Abdul Wahabb ${ }^{\mathrm{a}}$, Izni Iwani Majid ${ }^{\mathrm{b}}$, Haslina Taib ${ }^{\mathrm{a}}$ \\ ${ }^{a}$ School of Dental Sciences, Universiti Sains Malaysia, \\ 16150 Kubang Kerian, Kelantan, Malaysia \\ ${ }^{b}$ Periodontics Specialist Unit, Cahaya Suria Dental Clinic, 1st Floor, \\ Pudu Sentral Building, 55100 Kuala Lumpur, Malaysia \\ ${ }^{\star}$ Corresponding author: norsila@usm.my
}

To cite this article: Abdul Wahab N, Majid II, Taib H (2019). Periodontal disease in patients with type 2 diabetes and its relationship with dry mouth condition. Arch Orofac Sci, 14(2): 77-86. https://doi.org/10.21315/aos2019.14.2.380

To link to this article: https://doi.org/10.21315/aos2019.14.2.380

\begin{abstract}
This study aimed to determine the prevalence and severity of chronic periodontitis (CP) and the relationship between periodontal status and dry mouth condition in patients with type 2 diabetes mellitus (T2DM). A cross-sectional study was conducted on 66 controlled T2DM patients, determined by $\mathrm{HbAlc}$ level $\leq 9 \%$. Plaque index (PI), gingival index (GI), periodontal pocket depth (PPD), and clinical attachment loss (CAL) were recorded. Subjects were given questionnaire for self-evaluation of dry mouth followed by collection of saliva. Data were analysed using SPSS version 22.0. Results showed that the prevalence of CP was $93.9 \%$ with severity ranging from mild $(41.9 \%)$, moderate $(30.6 \%)$, to severe $(27.5 \%)$. Most subjects $(74.2 \%)$ had normal stimulated salivary flow rate although $15.9 \%$ reported having less saliva. There was no significant association between periodontal parameters and salivary flow rate. In conclusion, T2DM patients exhibited high prevalence of CP despite having controlled glycaemic status. Dry mouth condition was not a common symptom and was also not associated with periodontitis. To ensure appropriate management of diabetics, collaboration between medical colleagues and dental practitioners is important to control progression of periodontal disease.
\end{abstract}

Keywords: Diabetes mellitus; mouth dryness; periodontitis; xerostomia.

\section{INTRODUCTION}

Recently, a new definition for periodontitis has been published by Tonetti et al. (2018). The authors stated that the clinical definition for periodontitis is characterised by "microbially-associated, host-mediated inflammation that results in loss of periodontal attachment", which is detected as clinical attachment loss. Traditionally, periodontal disease is known as a chronic inflammation of the periodontium (which includes gingiva, periodontal ligament, alveolar bone, and root cementum) due to presence of bacterial plaque. It started as gingivitis and is reversible if patients can maintain good oral hygiene. However, if this condition is left untreated, the inflammation spreads to the underlying structures, causing tissue destruction and bone resorption (Flemmig, 1999). Thereafter, collagen fibres of the periodontal ligaments will break down, and periodontal pocket develops. Although these processes progress slowly, the 
tissue destruction that occurs is permanent (Seymour et al., 2015). Unfortunately, periodontal disease is very common, but its occurrence is often unnoticed by patients. In advanced stage, it negatively impacts many aspects of daily living and quality of life, in terms of confidence, social interactions, and food choices, such as having semisolid meals because patient cannot tolerate solids (O’Dowd et al., 2010).

Diabetes is one of the major risk factors for periodontitis (Preshaw et al., 2012), where diabetics are three to four times more likely to have periodontal disease compared to nondiabetics (Emrich et al., 1991). Prolonged tissue exposure to hyperglycaemia results in the production of advanced glycation end products, which leads to an increase in collagen cross-linking and the generation of reactive oxygen intermediates, such as free radicals. Over time, these collagen fibres accumulate in the tissues and thickened the basement membrane, a condition which could impair oxygen diffusion, waste elimination, leukocyte migration, and the diffusion of immune factors. These disorders would then contribute to the pathogenesis of periodontitis (Lalla et al., 1998; Molina et al., 2016).

Besides periodontitis, the other oral complication of diabetes mellitus (DM) is dry mouth condition, also known as xerostomia. It is defined as the subjective perception of dry mouth. The perception of dry mouth is sometimes, but not always, associated with a reduced salivary flow. The normal saliva quantity is important in the maintenance of the integrity of oral tissues, as saliva plays an important role in defense mechanism. The normal stimulated salivary flow rate is defined as a rate $\geq 1.0 \mathrm{ml} / \mathrm{min}$. Hyposalivation is considered when salivary flow rate is $<0.1 \mathrm{ml} / \mathrm{min}$ at rest or $<0.7$ $\mathrm{ml} / \mathrm{min}$ under stimulation (Navazesh and Kumar, 2008; Löfgren et al., 2012).

Dentists have long been aware of the importance of a diagnosis of diabetes in their patients, as many oral conditions are associated with this disease. Bajaj et al. (2012) reported that T2DM patients were observed to have periodontal disease $(34 \%)$, oral candidiasis $(24 \%)$, tooth loss $(24 \%)$, and dental caries $(24 \%)$. Other complications include xerostomia and salivary gland hypofunction in $14 \%$ of their subjects.

There is association between oral health and diabetes. Studies evaluating the association between the level of glycaemic control in patients with T2DM and their salivary flow reported that patients with poor glycaemic control produce less saliva (Chávez et al., 2000; Chávez et al., 2001). The authors speculated that the altered salivary flow rate in poorly-controlled DM is associated with autonomic neuropathies, hormonal imbalances, and microvascular changes (Chávez et al., 2000). They then extended their study in the elderly patients (aged 5490 years old) and reported similar findings; that is, older patients with poorly-controlled diabetes have impaired salivary flow when compared to better-controlled diabetes and non-diabetes. However, they did not report significant complaints of xerostomia (Chávez et al., 2001). Hoseini et al. (2017) also reported lower salivary flow rate and higher xerostomia in DM patients compared to healthy controls. The underlying aetiology of xerostomia may be due to systemic diseases such as endocrine, autoimmune, infectious, and granulomatous diseases (Millsop et al., 2017).

Although studies regarding relationship between periodontitis and DM are numerous in the field, the influence of these with dry mouth condition is under reported. We hypothesised that poor periodontal status is significantly correlated with dry mouth condition in diabetic patients. Thus, this study was conducted to assess the periodontal status and dry mouth condition in patients with controlled T2DM, determined by $\mathrm{HbA} 1 \mathrm{c}$ level $\leq 9 \%$. 


\section{MATERIALS AND METHODS}

This was a cross-sectional observational study on diabetic patients attending Hospital Universiti Sains Malaysia, Kelantan, Malaysia. The study protocol was approved by the Human Research Ethics Committee of USM, at which the study was conducted; reference number: USMKK/PPP/JEPeM [266.3.(13)]. All participants signed written informed consent and agreed to participate in the study. Patient's information was kept confidential by assigning numbers to each of them.

The inclusion criteria were patients with controlled T2DM determined by $\mathrm{HbA1c}$ level $\leq 9 \%$ (Tsai et al., 2002) and had been diagnosed with T2DM for more than three years. Patients with $\mathrm{HbA} 1 \mathrm{c}<7.0 \%$ will be considered as having well-controlled diabetes and the rest of the patients with $\mathrm{HbA} 1 \mathrm{c}>7 \%$ and $\leq 9 \%$ will be considered as having controlled diabetes. Patients with uncontrolled systemic diseases, pregnant, smokers, and those who have received periodontal treatment for the past three months prior to the study, were excluded.

The measurement of periodontal pocket depth and clinical attachment loss on one quadrant (where at least seven teeth were present) was done repeatedly on three patients by two examiners before the study started. The intra-examiner calibration was done on two patients with the same criteria. The reproducibility and reliability of the examiners were analysed using intra-class correlation coefficient. The results showed an agreement with Cronbach's alpha of 0.78 for inter-examiners and 0.85 for intra-examiner calibration.

From the medical records, patients who have recent $\mathrm{HbA} 1 \mathrm{c}$ level $\leq 9 \%$ were selected based on the inclusion and exclusion criteria. They were informed about the study and written informed consent was obtained. Patients were given an appointment at the dental clinic for oral examination. Prior to the appointment, they were advised to refrain from eating, drinking, and performing oral hygiene measures at least one hour before saliva collection. During the appointment, the assessment of dry mouth was done by using selfadministered questionnaire (Grisius and Fox, 1998) with the help of the researcher. Questions included were: (i) Do you have difficulty swallowing dry foods? (ii) Does your mouth feel dry while eating a meal? (iii) Do you sip liquids to aid in swallowing dry foods? and (iv) Does the amount of saliva in your mouth most of the time seem to be too little, too much, or you don't notice it?

The collection of stimulated saliva was carried out based on guidelines by Navazesh and Kumar (2008). The container and chewing gum were pre-weighted prior to data collection sessions. In upright position, patients chewed a chewing gum for two min to the sound of Metronome app (Mobile Metronome for Android version 1.2.4F) to standardise the chewing stroke at 65 beats/ min. The stimulated saliva was spit twice into the container, once after one $\min$ and another at the end of the two min. However, patients could spit more frequently if they were unable to hold their saliva in the mouth. Both container and chewing gum were then weighted again. The difference in weight was taken as the weight of saliva. The rate of stimulated salivary flow ( $\mathrm{mg} / \mathrm{min})$ was calculated by dividing this weight by two. The $\mathrm{mg} / \mathrm{min}$ unit is equivalent to $\mathrm{ml} / \mathrm{min}$, since over $99 \%$ of saliva is composed of water (Navazesh and Kumar, 2008).

Following saliva collection, periodontal assessment was carried out with the patient on the dental chair in supine position. The measurements of periodontal parameters such as plaque index (Silness and Loe, 1964), gingival index (Loe and Silness, 1963), probing pocket depth (PPD), and clinical attachment loss (CAL) were assessed using William's periodontal probe with grading of $1,2,3,5,7,8,9$, and $10 \mathrm{~mm}$, using gentle pressure (probe's power $=0.25 \mathrm{~N}$ ) and visual examination. Alveolar bone loss relative to root 
length (in millimetre) was measured from orthopantomogram radiograph using Planmeca Romexis software. The assessments were performed by a calibrated examiner and all data were recorded in a data collection form.

PPD and CAL were determined at six sites per tooth; that is, disto-buccal, mid-buccal, mesio-buccal, disto-lingual, mid-lingual, and mesio-lingual (Armitage, 2004). The PPD was measured using a periodontal probe, in which the depth from the gingival margin to the base of the pocket was recorded. The total PPD measurements from all teeth were then averaged to get a mean score for each subject.

CAL is the clinical parameter to detect loss of periodontal attachment and to determine the severity of periodontitis. It is measured from the cementoenamel junction (CEJ) to the base of the pocket (in millimetre) at six sites per tooth, as for PPD. When the CEJ can be seen clinically, CAL is calculated by adding the depth of periodontal pocket to the gingival recession measurement. Gingival recession is the distance between the CEJ and gingival margin. CAL measurements were then used to determine the presence of periodontal disease and its severity, based on the American Academy of Periodontology (1999) classification (Armitage, 1999). Chronic periodontitis (CP) is deemed to be localised when less than $30 \%$ of sites are affected and generalised when more than $30 \%$ of sites are affected. For severity of CP, it was considered mild when CAL is 1-2 $\mathrm{mm}$, moderate when CAL is $3-4 \mathrm{~mm}$, and severe when CAL is $\geq 5 \mathrm{~mm}$.

All data were entered and analysed using the Statistical Package for the Social Sciences (SPSS) version 22.0 software. Descriptive analyses of demographic variables were expressed as means and standard deviations (SD), or frequencies and percentages. The prevalence of periodontal disease was determined at $95 \%$ confidence interval (CI). Mann-Whitney test was used to compare the means of periodontal parameters between the different groups of $\mathrm{HbA} 1 \mathrm{c}$ level. Chi-squared test was used to test for association between the levels of the group's glycaemic control with (i) number of patients with PPD and (ii) salivary flow rate. The Pearson's correlation coefficient was used to determine the correlation between periodontal status and dry mouth condition in T2DM patients. A $p$ value of $<0.05$ was considered as statistically significant.

\section{RESULTS}

A total of 66 patients with the mean age of 54.9 (SD 6.71) years old participated in this study, in which $59 \%$ of them were males. More than $86 \%$ were Malays, who made up the majority of the population in this part of the country. The mean HbA1c level was $7.3 \%$ (SD 0.89). Out of the 66 patients, 26 $(39.4 \%)$ were in well-controlled diabetic status $(\mathrm{HbA} 1 \mathrm{c}<7.0 \%)$.

The prevalence of CP among T2DM patients was $93.9 \%$ (95\% CI: $0.88,1.0)$. Among them, 41.9\% had mild CP, 30.6\% moderate $\mathrm{CP}$, and $27.5 \%$ had severe CP based on CAL. There were $56(84.8 \%)$ patients presented with mean PPD $\geq 3 \mathrm{~mm}$. The records of periodontal parameters in these patients are shown in Table 1. Sixtythree percent of all patients presented with at least one site of PPD $\geq 5 \mathrm{~mm}$; most of them were in the HbAlc group of $\geq 7.0 \%$. However, there was no significant association between HbA1c level and PPD; $\chi^{2}(1)=0.57$, $p=0.812($ Table 2$)$.

Table 1 Periodontal status of the patients with pocket depth $\geq 3 \mathrm{~mm}(\mathrm{n}=56)$

\begin{tabular}{lcc}
$\begin{array}{l}\text { Periodontal } \\
\text { parameter }\end{array}$ & Mean (SD) & Range (min-max) \\
\hline $\mathrm{PI}$ & $1.68(0.52)$ & $0.5-3.0$ \\
$\mathrm{GI}$ & $1.88(0.52)$ & $0.4-3.0$ \\
$\mathrm{PPD}(\mathrm{mm})$ & $4.83(0.81)$ & $3.0-8.6$ \\
$\mathrm{CAL}(\mathrm{mm})$ & $3.69(1.46)$ & $2.1-9.1$ \\
\hline
\end{tabular}

$\mathrm{PI}=$ Plaque index $; \mathrm{Gl}=$ Gingival index $; \mathrm{PPD}=$ Probing pocket depth; $C A L=$ Clinical attachment loss. 
Table 2 The association between $\mathrm{HbA} 1 \mathrm{c}$ level and $\operatorname{PPD}(n=66)$

\begin{tabular}{lccccc|} 
Variable & $\begin{array}{c}\text { Mean } \\
\text { (SD) }\end{array}$ & $\begin{array}{c}\text { HbA1c }< \\
\mathbf{7 . 0 \%} \text { (n) }\end{array}$ & $\begin{array}{c}\text { HbA1c } \\
\mathbf{7 . 0 \%} \text { (n) }\end{array}$ & $\begin{array}{c}\boldsymbol{\chi}^{\mathbf{2}} \\
\text { (df) }\end{array}$ & $\begin{array}{c}\boldsymbol{p} \\
\text { value* }\end{array}$ \\
\hline PPD $<5 \mathrm{~mm}$ & $\begin{array}{c}3.44 \\
(1.85)\end{array}$ & 9 & 15 & 0.57 & 0.812 \\
& & & & $(1)$ & \\
PPD $\geq 5 \mathrm{~mm}$ & $\begin{array}{c}5.60 \\
(0.86)\end{array}$ & 17 & 25 & & \\
& & & & \\
\hline
\end{tabular}

*Chi-squared test, PPD = Periodontal pocket depth.

The mean stimulated salivary flow rate was 1.63 (SD 0.94) $\mathrm{mg} / \mathrm{min}$, in which $74.2 \%$ have a normal stimulated salivary flow rate $(\geq 1.0 \mathrm{mg} / \mathrm{min})$. Female subjects have slightly higher salivary flow rate compared to male subjects, 1.71 (SD 1.01) $\mathrm{mg} / \mathrm{min}$ and 1.58 (SD 0.82) $\mathrm{mg} / \mathrm{min}$, respectively. The salivary flow rate was slightly higher in patients with well-controlled DM [1.73 (SD 0.91) $\mathrm{mg} / \mathrm{min}$ ] compared to controlled DM group [1.59 (SD 1.01) $\mathrm{mg} / \mathrm{min}]$. However, it was found that there was no significant association between the level of $\mathrm{HbAlc}$ and salivary flow rate; $\chi^{2}(1)=2.414, p=0.12$. In terms of self-rated saliva quantity, most of the subjects rated as having normal amount of saliva (Table 3). Plaque index, gingival index, PPD, and CAL were not correlated with stimulated salivary flow rate among T2DM with periodontitis (Table 4).

\section{DISCUSSION}

The impact of DM to the periodontal tissues has been widely reported. The pathophysiological changes would likely be the reason for the higher prevalence of CP seen in this study, which coincides with a report from National Oral Health Survey of Adults 2010 (NOHSA 2010) in Malaysia (Oral Health Division, Ministry of Health Malaysia, 2013). Previous studies had also suggested that the risk of periodontitis in diabetic patients was higher compared to healthy patients (Emrich et al., 1991; Tsai et al., 2002; Mittal and Teeluckdharry, 2010; Garcia et al., 2015).
Table 3 Evaluation of the saliva quantity based on patient's perception $(n=66)$

\begin{tabular}{lc} 
Saliva quantity & Frequency (\%) \\
Normal & $30(45.5)$ \\
Much & $23(23.8)$ \\
Less & $11(16.7)$ \\
Not sure & $2(3.0)$ \\
\hline
\end{tabular}

Table 4 The association between stimulated salivary flow rate and periodontal parameters in patients with pocket depth $\geq 3 \mathrm{~mm}(n=56)$

\begin{tabular}{lcc}
$\begin{array}{l}\text { Periodontal } \\
\text { parameter }\end{array}$ & $\begin{array}{c}\text { Correlation coefficient } \\
(\boldsymbol{r})\end{array}$ & $\boldsymbol{p}$ value* \\
PI & 0.51 & 0.686 \\
$\mathrm{Gl}$ & 0.79 & 0.526 \\
$\mathrm{PPD}(\mathrm{mm})$ & 0.12 & 0.937 \\
$\mathrm{CAL}(\mathrm{mm})$ & -0.43 & 0.732 \\
\hline
\end{tabular}

*Pearson coefficient correlation test; $\mathrm{PI}=$ Plaque index; $\mathrm{Gl}=$ Gingival index $; \mathrm{PPD}=$ Probing pocket depth; $\mathrm{CAL}=$ Clinical attachment loss.

Saliva is an important fluid in the oral cavity; one of its many functions is to clear the oral cavity of bacteria, which could potentially harm the periodontium. Many studies have shown that DM and periodontal disease are biologically linked together (Preshaw et al., 2012; Casanova et al., 2014; Molina et al., 2016). Moreover, xerostomia and salivary gland hypofunction have also been reported in DM subjects (Chávez et al., 2000; Chávez et al., 2001; Moore et al., 2001; Bajaj et al., 2012), which could be more damaging to the periodontium. However, we could not find any association between CP and dry mouth condition in this study, probably because we studied patients who have controlled T2DM with HbAlc level $\leq 9.0 \%$ (Chávez et al., 2000; Tsai et al., 2002).

Various methods have been used to collect saliva. Salivary flow rates are usually measured for at least five min after an overnight fast or two hours after a meal (Löfgren et al., 2012). Other study proposed collection of saliva using pre-weighted cotton rolls at the orifice of major salivary glands, and re-weigh them after collection time (Leal 
et al., 2010). In this study, the collection of stimulated saliva was carried out based on guidelines by Navazesh and Kumar (2008). The stimulated saliva was induced by using chewing gum, instead of paraffin wax. The chewing gum was chosen as it is easier to chew, more widely available in the market, and more acceptable to the patients, compared to paraffin wax. As this study was designed to be used in a clinical setting in the future, the use of easily available chewing gum is a better option than paraffin wax. The chewing method is also the simplest way to assess salivary flow rate (Navazesh and Kumar, 2008). Stimulated salivation by chewing the gum increases the crevicular fluid, adding to the volume of saliva produced in these patients. Chewing gum is known to be one of the saliva stimulants for dry mouth, based on its mechanism of action of oral stimuli; namely, taste and mastication. Both of this stimulation provide instant relief from dry mouth as they increase salivation (Inui, 2015). Despite the advantages of using chewing gum, it may also influence the chewing masticatory stroke in patients with less number of teeth remaining in their mouth. Besides, the elderly patients seemed to be unfamiliar to gum chewing, which may affect the stimulation of saliva and its flow rate.

Whole saliva was collected as it is the most frequently used fluid to diagnose alterations in salivary output compared to saliva from a specific gland. It is a non-invasive procedure, cost-effective with limited training, and requires no special equipment for its collection. The early detection of salivary hypofunction will potentially be valuable for the management of xerostomia in preventing other oral and pharyngeal complications. Some older patients may not be aware of their reduced salivary flow due to dementia or other medical conditions; thus, this assessment would be of greater value in this population.

\section{Salivary Flow Rate and Dry Mouth Condition}

In this study, $25.8 \%$ of the patients had reduced salivary flow rate, which correlates with some studies that showed the prevalence of xerostomia in both T1DM and T2DM varies from $24 \%$ to $76 \%$ (Moore et al., 2001; Carda et al., 2006; Busato et al., 2012; Prathibha et al., 2013). However, there is considerable disagreement in the literature whether there is an effect of DM on alterations to salivary flow rates. Dodds and Dodds (1997) reported that patients with poorly-controlled T2DM did not have impaired salivary output. The authors found no differences in unstimulated and stimulated parotid saliva flow between diabetics and non-diabetics, although the unstimulated saliva was less in DM patients compared to non-diabetics. Nonetheless, they did not consider the medication taken by the patients, which could also influence the salivary output (Xu et al., 2019).

This study showed that controlled diabetes patients had a normal stimulated salivary flow rate, in line with Chávez et al. (2000) who reported similar findings. They mentioned that patients with poorlycontrolled diabetes (HbA1c $\geq 9 \%$ ) had lower stimulated parotid flow than patients with controlled diabetes and non-diabetes group. Moreover, the authors concluded that there was no significant difference in dry mouth complaints in terms of the level of glycaemic control and salivary flow rate. Since some of the patients in the present study presented with reduced salivation, this impairment could be related to the diabetes complications of neuropathy. Salivation is stimulated via the autonomic nervous system; thus, when neuropathies present, salivation may also be affected. Indeed, Carda et al. (2005) has demonstrated that acinar cells of the salivary gland are smaller in patients with DM.

Chávez et al. (2001) investigated salivary flow rate among diabetics who complained of xerostomia using a standardised xerostomia 
questionnaire. They reported that older people with poorly-controlled diabetes may have reduced salivary flow compared to better-controlled diabetes and normal people; however, there were more patients complaining of thirst rather than xerostomia. Thirst is associated with dehydration, and reduced salivary flow is also related to dehydration. Thus, it was suggested that thirst may be related to hypofunction of the salivary gland in these patients.

There may also be other variables that could influence the salivary flow which give rise to the different value in salivary flow rate; some of these were our study limitations. These factors include: (i) medication taken by the patients which has some xerogenic effects on the salivary flow, (ii) the time of saliva collection which was not at its peak production time, (iii) the difference in fluid or food intake prior to the test, and (iv) the amount of residual saliva that was swallowed during saliva collection. In this present study, timing of saliva collection was set in the morning between 8.30 am to 11.30 am, although there were a few patients who could not conform to it.

\section{Association between Periodontal Parameters and Dry Mouth Condition}

The present study found no association between periodontal parameters and dry mouth condition in the study subjects. Although the prevalence of CP is high, it does not show any effect on the salivary flow rate which was found to be within the normal range. In contrast, Farsi et al. (2008) found an association between periodontitis and salivary flow rate; hence, concluded that periodontal disease is strongly linked to salivary flow rate. Meanwhile, Márton et al. (2008) who assessed the prevalence of xerostomia and its relation to other symptoms of oral dryness suggested that subjects with less saliva might have a higher risk for caries and gingivitis, but not for periodontitis. They also reported that gingival bleeding and plaque indices were significantly higher in patients with low saliva; thus, there is an increased risk for plaque build-up and gingivitis in patients with hyposalivation. The salivary flow rate and periodontitis was not significantly associated in this present study.

There are some arguments on how the dry mouth can increase the risk of periodontitis. When there is reduced saliva, there will be an increase in bacterial plaque accumulation and food debris, as the cleaning effect of saliva is affected (Dodds et al., 2015). This might predispose the subject to periodontal disease. Moreover, the high glucose environment in diabetes patients can possibly alter the plaque microflora which favours the periodontal pathogen, thus increasing the risk for periodontal destruction. It was thought that saliva does not have a direct influence on periodontal pathogens within the periodontal pocket since there is an outward flow of crevicular fluid, and the antibacterial components that are contained in the saliva are able to fight against the pathogenic periodontal pathogens (Faran Ali and Tanwir, 2012). However, in patients with reduced salivary flow, bacterial clearance is reduced; therefore, there will be more bacterial colonisation on the periodontal tissue. In this study, subjects with normal stimulated salivary flow rate were the majority; hence, the presence of CP could be due to dental biofilm and other factors, for example diabetic status, age, and oral hygiene. Plaque accumulation has been shown to be associated with CP (Lertpimonchai et al., 2017).

\section{CONCLUSION}

This present study concluded that: (i) there was high prevalence of CP in controlled T2DM patients with moderate to advanced stage of severity, (ii) controlled T2DM patients have normal salivary flow rate, and (iii) there was no association between periodontal disease and dry mouth condition in controlled T2DM patients. Both dental and medical counterparts should collaborate to improve patient care; referral both ways 
are critical in the management of these patients. The periodontal examination needs to be a part of diabetes management and assessment. If glycaemic status does have effects on salivary dysfunction, then preventive and intervention therapy will be necessary to reduce the related oral problems. Therefore, early referral by medical colleagues for dental assessment is crucial to prevent and control the disease progression, thus improving quality of life of the patients.

\section{ACKNOWLEDGMENTS}

The study is supported by Universiti Sains Malaysia Short-Term Grant, project code number 304/PPSG/61313013.

\section{REFERENCES}

Armitage GC (1999). Development of a classification system for periodontal diseases and conditions. Ann Periodontol, 4(1): 1-6. https://doi.org/10.1902/ annals.1999.4.1.1.

Armitage GC (2004). The complete periodontal examination. Periodontol 2000, 34: 22-33. https://doi.org/10.1046/j.09066713.2002.003422.x.

Bajaj S, Prasad S, Gupta A, Singh VB (2012). Oral manifestations in type-2 diabetes and related complications. Indian $\mathcal{f}$ Endocrinol Metab, 16(5): 777-779. https://doi. org/10.4103/2230-8210.100673.

Busato IM, Ignácio SA, Brancher JA, Moysés ST, Azevedo-Alanis LR (2012). Impact of clinical status and salivary conditions on xerostomia and oral health-related quality of life of adolescents with type 1 diabetes mellitus. Community Dent Oral Epidemiol, 40(1): 62-69. https://doi.org/10.1111/ j.1600-0528.2011.00635.x.
Carda C, Carranza M, Arriaga A, Díaz A, Peydró A, Gomez de Ferraris ME (2005). Structural differences between alcoholic and diabetic parotid sialosis. Med Oral Patol Oral Cir Bucal, 10(4): 309-314.

Carda C, Mosquera-Lloreda N, Salom L, Gomez de Ferraris ME, Peydró A (2006). Structural and functional salivary disorders in type 2 diabetic patients. Med Oral Patol Oral Cir Bucal, 11(4): E309-E314.

Casanova L, Hughes FJ, Preshaw PM (2014). Diabetes and periodontal disease: A two-way relationship. $\mathrm{Br}$ Dent $\mathcal{F}, 217(8)$ : 433-437. https://doi.org/10.1038/ sj.bdj.2014.907.

Chávez EM, Borrell LN, Taylor GW, Ship JA (2001). A longitudinal analysis of salivary flow in control subjects and older adults with type 2 diabetes. Oral Surg Oral Med Oral Pathol Oral Radiol Endod, 91(2): 166-173. https://doi.org/10.1067/ moe.2001.112054.

Chávez EM, Taylor GW, Borrell LN, Ship JA (2000). Salivary function and glycemic control in older persons with diabetes. Oral Surg Oral Med Oral Pathol Oral Radiol Endod, 89(3): 305-311. https://doi. org/10.1016/S1079-2104(00)70093-X.

Dodds MW, Dodds AP (1997). Effects of glycemic control on saliva flow rates and protein composition in non-insulindependent diabetes mellitus. Oral Surg Oral Med Oral Pathol Oral Radiol Endod, 83(4): 465-470. https://doi.org/10.1016/S10792104(97)90147-5.

Dodds M, Roland S, Edgar M, Thornhill M (2015). Saliva: A review of its role in maintaining oral health and preventing dental disease. BDf Team, 2:15123. https://doi.org/10.1038/bdjteam.2015.123.

Emrich LJ, Shlossman M, Genco RJ (1991). Periodontal disease in non-insulindependent diabetes mellitus. I Periodontol, 62(2): 123-131. https://doi.org/10.1902/ jop.1991.62.2.123. 
Faran Ali SM, Tanwir F (2012). Oral microbial habitat a dynamic entity. F Oral Biol Craniofac Res, 2(3): 181-187. https://doi. org/10.1016/j.jobcr.2012.07.001.

Farsi N, Al Amoudi N, Farsi J, Bokhary S, Sonbul H (2008). Periodontal health and its relationship with salivary factors among different age groups in a Saudi population. Oral Health Prev Dent, 6(2): 147-154.

Flemmig TF (1999). Periodontitis. Ann Periodontol, 4(1): 32-38. https://doi. org/10.1902/annals.1999.4.1.32.

Garcia D, Tarima S, Okunseri C (2015). Periodontitis and glycemic control in diabetes: NHANES 2009 to 2012. $\mathcal{F}$ Periodontol, 86(4): 499-506. https://doi. org/10.1902/jop.2014.140364.

Grisius MM, Fox PC (1998). Salivary gland dysfunction and xerostomia. In: Linden RWA (ed.). The Scientific Basis of Eating: Taste, Smell, Mastication, Salivation and Swallowing and Their Dysfunctions, Front Oral Biol, Vol 9. Basel: Karger, pp. 156167. https://doi.org/10.1159/isbn.978-3318-00239-3.

Hoseini A, Mirzapour A, Bijani A, Shirzad A (2017). Salivary flow rate and xerostomia in patients with type I and II diabetes mellitus. Electron Physician, 9(9): 52445249. https://doi.org/10.19082/5244.

Inui $\mathrm{T}$ (2015). The beneficial effects of regular chewing. In: Carpenter G (ed.). Dry Mouth: A Clinical Guide on Causes, Effects and Treatments. Berlin, Heidelberg: Springer, pp. 175-194.

Lalla E, Lamster IB, Schmidt AM (1998). Enhanced interaction of advanced glycation end products with their cellular receptor RAGE: Implications for the pathogenesis of accelerated periodontal disease in diabetes. Ann Periodontol, 3(1): 13-19. https://doi. org/10.1902/annals.1998.3.1.13.
Leal SC, Bittar J, Portugal A, Falcão DP, Faber J, Zanotta P (2010). Medication in elderly people: Its influence on salivary pattern, signs and symptoms of dry mouth. Gerodontology, 27(2): 129-133. https://doi. org/10.1111/j.1741-2358.2009.00293.x.

Lertpimonchai A, Rattanasiri S, Arj-Ong Vallibhakara S, Attia J, Thakkinstian A (2017). The association between oral hygiene and periodontitis: A systematic review and meta-analysis. Int Dent $\mathcal{F}, 67(6)$ : 332-343. https://doi.org/10.1111/idj.12317.

Loe H, Silness J (1963). Periodontal disease in pregnancy. I. Prevalence and severity. Acta Odontol Scand, 21: 533-551. https:/doi. org/10.3109/00016356309011240.

Löfgren CD, Wickström C, Sonesson M, Lagunas PT, Christersson C (2012). A systematic review of methods to diagnose oral dryness and salivary gland function. BMC Oral Health, 12:29. https://doi. org/10.1186/1472-6831-12-29.

Márton $\mathrm{K}$, Madléna M, Bánóczy J, Varga G, Fejérdy P, Sreebny LM et al. (2008). Unstimulated whole saliva flow rate in relation to sicca symptoms in Hungary. Oral Dis, 14(5): 472-477. https://doi. org/10.1111/j.1601-0825.2007.01404.x.

Millsop JW, Wang EA, Fazel N (2017). Etiology, evaluation, and management of xerostomia. Clin Dermatol, 35(5): 468-476. https:/doi. org/10.1016/j.clindermatol.2017.06.010.

Mittal M, Teeluckdharry H (2010). Prevalence of periodontal diseases in diabetic and nondiabetic patients: A clinical study. Internet f Epidemiol, 10(1).

Molina CA, Ojeda LF, Jiménez MS, Portillo CM, Olmedo IS, Hernández TM et al. (2016). Diabetes and periodontal diseases: An established two-way relationship. f Diabetes Mellitus, 6: 209-229. https://doi. org/10.4236/jdm.2016.64024. 
Moore PA, Guggenheimer J, Etzel KR, Weyant RJ, Orchard T (2001). Type 1 diabetes mellitus, xerostomia, and salivary flow rates. Oral Surg Oral Med Oral Pathol Oral Radiol Endod, 92(3): 281-291. https://doi. org/10.1067/moe.2001.117815.

Navazesh M, Kumar SK (2008). Measuring salivary flow: Challenges and opportunities. f Am Dent Assoc, 139(Suppl): 35S-40S. https://doi.org/10.14219/jada. archive.2008.0353.

O'Dowd LK, Durham J, McCracken GI, Preshaw PM (2010). Patients' experiences of the impact of periodontal disease. $\mathcal{F}$ Clin Periodontol, 37(4): 334-339. https://doi. org/10.1111/j.1600-051X.2010.01545.x.

Oral Health Division, Ministry of Health Malaysia (2013). National Oral Health Survey of Adults 2010 (NOHSA 2010). Putrajaya: Oral Health Division, Ministry of Health Malaysia.

Prathibha KM, Johnson P, Ganesh M, Subhashini AS (2013). Evaluation of salivary profile among adult type 2 diabetes mellitus patients in South India. $\mathcal{f}$ Clin Diagn Res, 7(8): 1592-1595. https://doi. org/10.7860/JCDR/2013/5749.3232.

Preshaw PM, Alba AL, Herrera D, Jepsen S, Konstantinidis A, Makrilakis $\mathrm{K}$ et al. (2012). Periodontitis and diabetes: A twoway relationship. Diabetologia, 55(1): 2131. https://doi.org/10.1007/s00125-0112342-y.
Seymour GJ, Berglundh T, Trombelli L (2015). Pathogenesis of periodontitis. In: Lindhe J, Lang NP (eds.). Clinical Periodontology and Implant Dentistry, 6th edn. New York: John Wiley \& Sons Inc., pp. 256-365.

Silness J, Loe H (1964). Periodontal disease in pregnancy II. Correlation between oral hygiene and periodontal condition. Acta Odontol Scand, 22(1): 121-135. https://doi. org/10.3109/00016356408993968.

Tonetti MS, Greenwell H, Kornman KS (2018). Staging and grading of periodontitis: Framework and proposal of a new classification and case definition. f Periodontol, 89(Suppl 1): S159-S172. https://doi.org/10.1002/JPER.18-0006.

Tsai C, Hayes C, Taylor GW (2002). Glycemic control of type 2 diabetes and severe periodontal disease in the US adult population. Community Dent Oral Epidemiol, 30(3): 182-192. https://doi. org/10.1034/j.1600-0528.2002.300304.x.

Xu F, Laguna L, Sarkar A (2019). Aging-related changes in quantity and quality of saliva: Where do we stand in our understanding? f Texture Stud, 50(1): 27-35. https://doi. org/10.1111/jtxs. 12356 . 